\section{Recombination: tale and technique}

\author{
I. Barry Holland
}

Recombinant DNA: A Short Course.

By James D. Watson, John Tooze and David T. Kurtz.

W. H. Freeman: 1983. Pp.260.

Hbk \$27.95, £25.95; pbk \$17.95, £15.50.

Recombinant DNA Techniques: An Introduction.

By Raymond L. Rodriguez and Robert C. Tait.

Addison-Wesley: 1983. Pp.236.

Pbk \$21.95, f16.95.

IN Recombinant DNA, James Watson and his co-authors have come up with a delightful book, not only to read but to look at since it is brilliantly illustrated in the Scientific American mould. The major developments in the story of molecular biology are succinctly put in their historical context, clearly and with no frills, leaving the reader free to pursue the underlying evidence from the reading lists provided.

Importantly, coverage is well up to date, the book including most of what the general biologist and first-year undergraduate would want to know about the principles of the recombinant DNA approach to research. How this approach is paying off is exemplified by accounts of antibody formation, transposable elements in pro- and eukaryotes, tumour viruses and the basis of cancer and other human diseases. The authors then move more specifically into the exploitation of recombinant DNA technology for application in biotechnology. This material is again presented incisively and with great polish, but almost exclusively in terms of cloning, manipulating and re-implanting mammalian genes.

In the final chapter on specific industrial applications, the scope is even more exclusive, being restricted to the production of viral and human proteins by Escherichia coli. This limits the value of the book to some extent, since clearly this is but the tip of the iceberg of the potential of the techniques and genetic systems so exquisitely portrayed in the earlier chapters. This chapter is also marred by the misconception that $E$.coli secretes proteins into the medium as a matter of course while biotechnologists might wish that this were the case, the molecular biologist still finds it a challenging problem that only very rare proteins have the ingenuity to negotiate the double membrane of $E$. coli. But, in all, this is a captivating book which should (and will) be read by a far wider range of people than undergraduate students.

Despite the similarity of the titles, Rodriguez and Tait's Recombinant DNA Techniques is an entirely different book. In

it, the authors have set out to provide guidance in basic techniques for advanced undergraduates, post-graduates and others just beginning to get to grips with recombinant DNA technology.

Techniques in modern molecular biology are dangerously addictive, often more fascinating than some of the questions they are designed to illuminate. Moreover a laboratory may have just one method, refined to perfection, which stubbornly refuses to work in your own laboratory. Whole careers may be felt to depend upon the acquisition of the latest plasmid mini-prep procedure, sequencing short cut, cloning protocol or gene expression system - hence the enthusiasm to acquire manuals of techniques on the one hand and to write them on the other. Herein lies the rub! How does one present a topic, inherently boring when read, in a form and style which will engender sufficient comprehension to convince the inquisitive practitioner to sample the procedures?

Rodriguez and Tait's book consists of a series of lengthy discussions of some very basic cloning procedures - isolation and ligation of DNA, bacterial transformation and gel electrophoresis, for example punctuated by exercises based upon the

\section{Not too many cooks}

\section{John G. Edwards}

Cell Biology: Structure, Biochemistry, and Function, 2nd Edn.

By Phillip Sheeler and Donald E. Bianchi.

Wiley: 1983. Pp.668. £13.95, \$19.60.

Cell Biology, 3rd Edn.

By John W. Kimball.

Addison-Wesley: 1983. Pp.330.

$\$ 25.95, £ 22.05$.

Cells, 2nd Edn. By Michael W. Berns.

Saunders: 1983. Pp.256.

Pbk \$15.95, £7.95.

Laboratory Investigations in Cell Biology.

By Allyn A. Bregman.

Wiley: 1983. Pp.253.

Pbk £13.95, \$19.50.

FOR several years Cell Biology has been a fashionable label for textbooks which place an outline of biochemistry in juxtaposition with or (if you were lucky) in the context of cell structure. Very variable is the extent to which authors have really shifted cells to centre stage by telling us about the sorts of things they do. My suspicion, reinforced by reading the three new editions reviewed here, is that the range and rate of change of such material is too great, however heroic the attempt, for packaging by one or even two authors.

So the main development to consider since the previous editions of the three texts is not so much the advance of test-tube cloning and characterization of $E$. coli genes in general and the histidine and arabinose operons in particular. The approach is descriptive and requires close attention on the part of the reader to follow the dense narrative style through to the practical diversions. Accessibility is not helped by the closely lined format of the text.

The exercises themselves are more clearly laid out in recipe style, but a drawback is that there is a tendency to assume that many of the experiments will be approached sequentially; there is little discussion of trouble-shooting or comparative evaluation of different techniques. There are useful lists of restriction and DNA modifying enzymes, plasmids with maps and sequences and bald protocols on DNA technologies (several of which are culled directly from earlier publications). Nevertheless this aspect (which takes one-third of the text) is the best feature of a book which otherwise suffers from a very specialist appeal and an apparent desire to be read rather than used.

I. Barry Holland is Professor of Genetics at the University of Leicester and Acting Director of the Leicester Biocentre.

genetics, which each has set out to accommodate, but the arrival on the scene of the six-author Molecular Biology of the Cell by Bruce Alberts et al. (Garland, 1983; for review see Nature 302,$637 ; 1983)$. This book has shown for the first time the full potential of cell-centred biological education.

The view downwards, from cells through organelles (impressively handled) to molecules, is dominant in Sheeler and Bianchi. The book has very good diagrams, a useful chapter on research tools (especially radioisotopes and cell-fractionation) and a newly added chapter on molecular genetics. The problem of range of material naturally shows most in the handling of grey areas. The authors occasionally slip into representing hypothesis as fact; no hint here that the microtrabecular lattice is controversial, that the tilting of myosin on actin is still model rather than measurement, or that contact inhibition is probably not what it seems.

Kimball's niche is distinctly different, the book consisting chiefly of the sections on biochemistry and genetics taken from a larger work (Biology, 5th Edn; for review see p.128). I imagine there may be many first-year students who would enjoy the engagingly direct, almost conversational text. Some of the illustrations (of an Ames test, a sequencing gel, a DNA clone) score hits, and this seems a good place to meet the immune system. The superb cover illustration of cytoskeletal filaments is rather misleading, however, because this area is thinly covered (organelles as such occupy only 20 pages), and there is no account of 